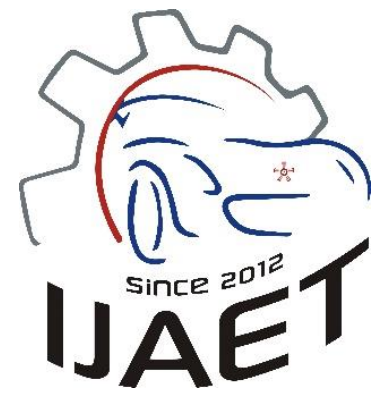

e-ISSN: 2146 - 9067

International Journal of Automotive

Engineering and Technologies

journal homepage:

https://dergipark.org.tr/en/pub/ijaet

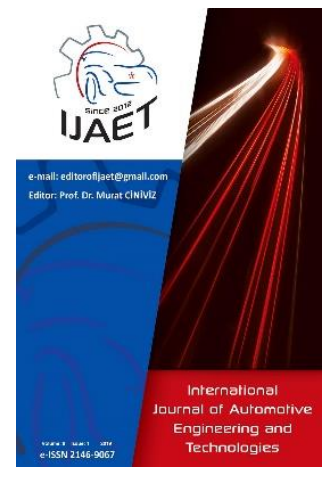

Original Research Article

\title{
An experimental approach to comparative thermal behavior of rubber and metallic clutch dampers
}

\author{
Mehmet Onur Genç ${ }^{1}$ *, Süleyman Konakçı², Necmettin Kaya ${ }^{3}$ \\ $1 *, 2$ Valeo Automotive Systems, Bursa, Turkey \\ ${ }^{3}$ Bursa Uludağ University, Depertmant of Mechanical Engineering, Bursa, Turkey
}

\section{ARTICLE INFO \\ 1 0000-0003-0332-1785 \\ 2 0000-0003-1552-5486 \\ 3 0000-0002-8297-0777 \\ Doi: 10.18245/ijaet.750130 \\ * Corresponding author mehmetonurgenc@gmail.com}

Received: Jun 11, 2020

Accepted: Nov 26, 2020

Published by Editorial Board Members of IJAET

(C) This article is distributed by Turk Journal Park System under the CC 4.0 terms and conditions.

\begin{abstract}
Clutch is one of the most important components in automobile powertrain systems. The torque generated in an engine is transmitted by friction faces of a clutch disc between pressure plate and flywheel. In addition to transmitting engine torque, the clutch disc has the task of preventing torsional engine vibrations from reaching the powertrain. To achieve this task, the clutch disc is fitted with torsional dampers which have metallic compression springs. Another solution is to use rubber springs instead of metallic ones. Recently rubber materials are widely demanded particularly in the automotive industry with the advantages of high damping capability, lightweight and low cost. In a traffic jam condition, numerous engagement and disengagement create incremental thermal load and temperature increase due to slippage between friction faces. The temperature level in the clutch house is expected to affect material properties of damping components assembled inside the clutch disc. In this paper, the rubber and metallic damper springs were investigated experimentally at the expected temperatures and dynamic loads during driving conditions. Thus, the thermal behavior of rubber springs in the clutch system was observed with the novel approach. Damper torque characteristics, cooling rates and loss of stiffness change with time and frequency have been revealed comparatively. Safety factor coefficient selection for damper torque has the major importance at the system in which the stiffness varies within time due to dynamic loads. In conclusion, the clutch disc used with rubber springs needs correct analysis in terms of design. Results show that how to safety actor should be chosen more attentively for clutch disc used with rubber spring on automobiles and related calculations have to be done before the design phase.
\end{abstract}

Keywords: Rubber spring, Metallic spring, Clutch disc, Powertrain system, Clutch thermal behavior

\section{Introduction}

The clutch in the powertrain system has high importance in automobiles and provides torque transmission. The flywheel is bolted to the engine crankshaft and clutch cover assembly bolted to the flywheel. During engagement, the clutch disc (Fig. 1) is clamped between the pressure plate of clutch cover assembly and flywheel, resulting in torque flow from the engine to the transmission. Figure 1 also shows the clutch disc design with metallic and rubber damper design which are comparatively investigated in terms of thermal behavior in this 
study. The prototypes having rubber and metallic dampers consist of same components and design except damper springs made of metal and rubber.

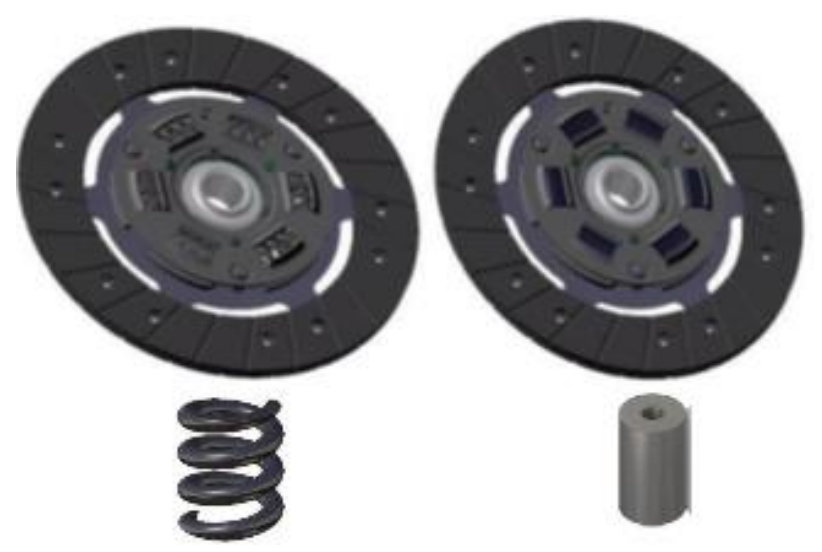

Figure 1. Clutch damper disc with metallic \& rubber springs

Under driving conditions between engine and transmission relative motions occur between engine and transmission due to dynamic variables. Relative motion between flywheel and clutch disc causes slippage that leads to dissipated energy. During slippage, thermal load in clutch house increases and this may cause permanent or temporary changes on material properties of the components. The dissipated energy and wear on friction materials increase with slipping duration. Under normal working conditions, the amount of kinetic energy converted into heat leads to temperature increase (Fig. 2). Figure 2 belongs to real vehicle test results obtained with thermal sensors via acquisition box such as LMS Scadas.

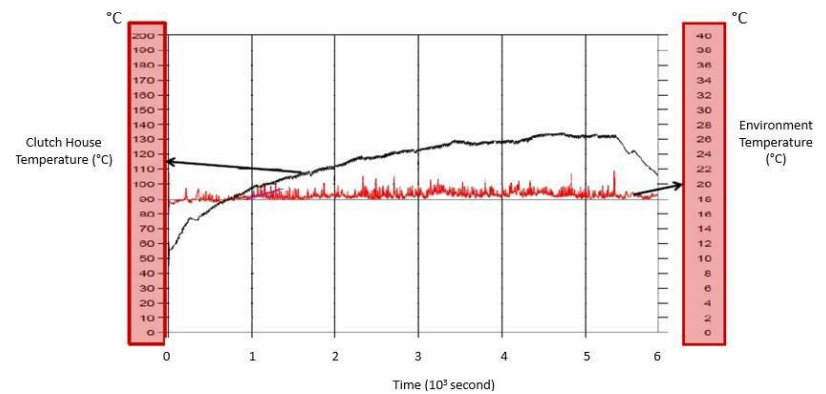

Figure 2. Experimental thermal measurements in the clutch house during driving at traffic jam conditions

(Vehicle test data in Valeo Plant)

Torque transmission $\mathrm{T}(\mathrm{t})[\mathrm{Nm}]$ is proportional to clamp load $\mathrm{F}[\mathrm{N}]$, friction coefficient $\mu$, the number of friction faces $\mathrm{N}$ and mean radius $\mathrm{Rm}$ (Eq. 1).

$T=F \cdot \mu \cdot N \cdot R \cdot m$

Generated heat flux during the slippage phase is distributed between flywheel and clutch based on their thermal diffusivity. The heat is transferred by conduction between the solid parts depending on their specific heat $\mathrm{Cp}[\mathrm{J} / \mathrm{kgK}]$ and mass $\mathrm{M}[\mathrm{kg}]$ (Eq. 2). Q stands for the heat transfer in unit of Joule $(\mathrm{J})$ and $\Delta \mathrm{T}$ equals the temperature change during heat transfer.

$Q=M \cdot c_{p} \cdot \Delta T$

The main duty of the clutch disc is to damp torsional vibrations coming from the engine. Therefore, some damping components such as metallic springs are conventionally used in the clutch disc. Figure 3 shows the view of metallic \& rubber springs using in clutch damper discs. Metallic springs have some disadvantages such as metal to metal frictions, early breakages related to wear and high stiffness. These situations require the modeling of rubbers as a damping element in clutches. However, rubber materials have viscoelastic properties that need attention during modeling such as 'Mullins effect' which is called as stress softening behavior of cross-linked rubbers at first cycles. Rubber materials are widely used in the automotive industry due to their damping properties. The rubbers are in the group of polymer-based materials and their mechanical behaviors change with time, temperature and frequency more sensitively than steels. Except for steel like materials, rubbers contain polymer chains in which internal damages occurred as a function of time under operational conditions. These properties need to be well modeled and designed to prevent deterioration during dynamic system conditions.

Many researchers in literature have investigated the clutch disc springs in the powertrain systems and rubber modeling. Adamowicz [1] investigated the heat increase and thermal stress in frictional parts under transient conditions. He made detailed analysis of thermal behaviors and enables this analysis comparative to another frictional system which is clutch dampers. Gkinis et al. [2] studied the thermal behaviors of the dry clutch systems with its major parameters such as friction between clutch disc and casting products which are pressure plate and flywheel. They also observed the heat condition and thermal loads in clutch house. Zhang and Zhang [3] investigated the deterioration and the parameters of the thermal behavior of the rubber 
caused by the working conditions in the rubber bushes used in aviation or vehicles to reduce noise and vibration. The data obtained at different frequency and amplitude values are modeled by the temperature-dependent change in viscoelastic behavior. Melnik et al. [4] investigated the nonlinear properties of rubbers in material dynamics and investigated the effects of these properties on the thermal behavior of rubbers under high frequency concerning time, temperature and displacement. Zhang and Zhang [5] studied the viscoelastic parameters of rubber bushes and used thermal analysis in this method, which determines their physical properties by DMA (Dynamic Mechanical Analysis). A new approach to the prediction of hysteresis losses based on the interaction between molecular chains of polymer structures has been proposed. Bani et al. [6] observed the temperature of increased rubber-metal springs under loading conditions and observed heat accumulation due to hysteresis losses and low rubber thermal conductivity resulting from increased temperature. They categorized physical and chemical impairments as a result of heat accumulation, which is the main cause of aging in rubber, and points out that the increase in hardness and the decrease in damping ability. Genç and Kaya [7] investigated the elastomer damper design under various conditions in their study. They used NBR rubber material in their rubber spring. According to their results, in case of full elastomer damper was used with NBR material, the clutch damper tents to loose $15 \%$ stiffness in first $10 \mathrm{~K} \mathrm{~km}$ driving. These results show the sensitive design necessity of rubber dampers in automotive clutch system due to stiffness losing issue.

Monsia [8] studied the model of a customized Maxwell viscoelastic material consisting of a nonlinear shear connected in series with a dashpot to model the time-dependent properties of various viscoelastic materials and described the steps of the mathematical model. Mohammed [9] studied the modeling of a soft rubber material as visco-hyperelastic. The visco-hyperelastic model is represented by the combination of the viscoelastic prony series. Pacheco et al. [10] investigated the mechanical behavior of viscoelastic materials by variables such as time and temperature in addition to other factors. Experimental data using the prony series of viscoelastic relaxation behavior and experimental results were compared to confirm the methodology based on the time effect of the analysis results. Wu et al. [11] in this study modeled rubber by using the finite element analysis method and Ogden hyperelastic material model, they also obtained experimental data with single axis, biaxial tests and simple sliding test. Ali et al. [12] studied different structural models for rubber-like materials that underwent extensive deformation in their work. Stress-strain characteristics were obtained by hyperelastic material modeling using finite element analysis in structural modeling, and their priorities were defined in the selection of material-appropriate hyperelastic material models. Abubakar et al. [13] studied rubber materials used in many engineering applications, such as sealing components and studied methods for accurate estimation of the response of rubbers to loads. They have presented an approach to obtain rubber material properties under compression loading based on hyperelastic strain formulation through experimental testing and finite element modeling in the study. Jadhav et al. [14] studied the hyperelastic modeling of the mechanical behaviors of rubber materials, such as natural rubber and silicone, and rubber materials, ranging from muscles to biological materials such as skin texture, by hyperelastic modeling. Kaya [15] investigated the stiffness behaviors of rubber bushings by using the differential evolutionary algorithm. Also, shape optimization of rubber bushing was investigated with the rubber material testing methodology, then the target geometry was found based on population evolutionary. Marvalova [16] experimentally measured the viscoelastic stress response by characterizing the mechanical behavior of rubber structures in deformation processes under isothermal conditions. Viscoelastic stress relaxation behavior was investigated by examining the structural function parameters under variable frequencies. Sun et al. [17] studied nonlinear stiffness characteristics of 'Dual Mass Flywheel (DMF) and highlighted its advantages mostly in diesel engines compared to conventional clutch disc. Damper systems are subjected to various dynamic conditions, and the material of damper 
springs have to be chosen attentively by considering thermal operational loads. In order to achieve this task, in this study, the advantages and disadvantages of both springs have revealed and indicated with the experimental functional bench test results which simulates the real driving condition on the road in terms of thermal behavior. This paper makes a novel approach to rubber damper springs behavior under thermal condition comparatively with metal springs by mentioning their advantages and disadvantages and contributes to developing of the thermal test procedure of rubber spring.

\section{Compression Test at Various Temperatures}

In this section the compression test results are compared for rubber and metal spring components. Rubber-based materials consist of polymer chains which need well-defined material characterization. Dynamic conditions such as frequency compression, thermal load create breakages on the polymer chains, and it affects the robustness of the material which has effects on the stiffness property. In this section, the compression test has been performed to obtain the compression test characteristic. ASTM standard has been taken into consideration for this purpose, because the elastomeric samples are sensitive to mechanical deviations in terms of test validations. However, in Section 3 (Furnace test), the used rubber samples are specific to clutch design that the rubbers are used in. Therefore, prepared samples according to ASTM standart were just used for material characterization in this study. Each test sample is prepared with $25.4 \mathrm{~mm}$ in diameter and $12.7 \mathrm{~mm}$ in length. Figure 3 shows the test specimen and the test machine prepared according to ASTM D695 standards. The compression test machine used in this study enables to measure up to $30.000(30 \mathrm{~K}) \mathrm{N}$ compression test reaction force. The test specimens prepared according to ASTM D695 were measured in this machine with software control.

In this section, the comparative test results were investigated and evaluated. The main point in this section is the stiffness sensitivity of rubberbased materials due to deteriorations on polymer chains. As opposite, metallic springs are more constant in terms of stiffness when the spring is subjected to dynamic forces such as thermal load. Test samples were subjected to a compression test at various temperatures. Figure 4 shows a brief graph between Force $(\mathrm{N})$ and Displacement $(\mathrm{mm})$. The furnace was used to heat the rubbers under the closed chamber. After the heating phase, test samples were taken and the compression test was performed at the compression test machine.

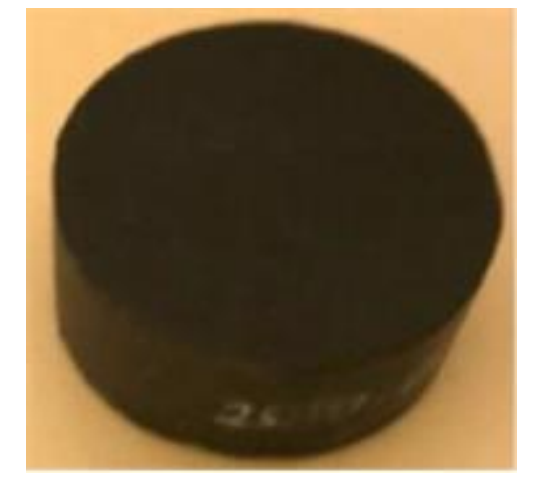

a) Test specimen according to ASTM D695 standart

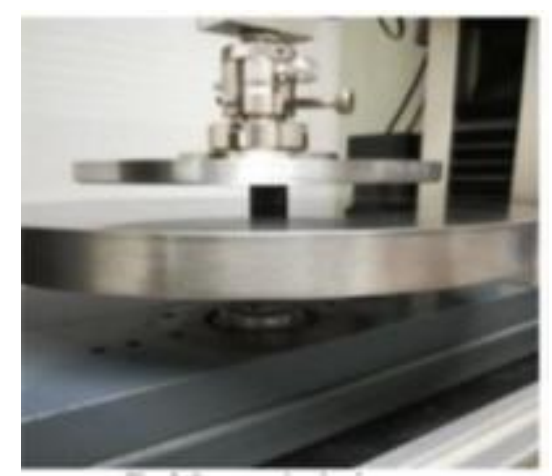

b) Compression Test Machine

Figure 3. Compression test specimen and test machine

In this section, the comparative test results were investigated and evaluated. The main point in this section is the stiffness sensitivity of rubberbased materials due to deteriorations on polymer chains. As opposite, metallic springs are more constant in terms of stiffness when the spring is subjected to dynamic forces such as thermal load. Test samples were subjected to a compression test at various temperatures. Figure 4 shows a brief graph between Force $(\mathrm{N})$ and Displacement $(\mathrm{mm})$. The furnace was used to heat the rubbers under the closed chamber. After the heating phase, test samples were taken and the compression test was performed at the compression test machine.

NBR based rubber test specimens were showed progressive stiffness loss. This situation gives an idea to take some countermeasures in case the rubber is used in the clutch disc at driving conditions. Table 1 indicates the force values 
Table 1. Comparative rubber compression test at various temperatures

\begin{tabular}{ccccc}
\hline $\begin{array}{c}\text { Sample } \\
\text { No }\end{array}$ & $\begin{array}{c}\text { Temperature } \\
\left({ }^{\circ} \mathbf{C}\right)\end{array}$ & $\begin{array}{c}\text { Duration } \\
\text { (Minutes) }\end{array}$ & $\begin{array}{c}\text { Force at } 5 \text { mm compression on } \\
\text { standard test specimen }(\mathbf{N})\end{array}$ & $\begin{array}{c}\text { Loss of force at 5 mm } \\
\text { compression compare to } \\
\text { room temperature }(\%)\end{array}$ \\
\hline $\mathbf{1}$ & 24 & - & 3286 & - \\
$\mathbf{2}$ & 50 & 60 & 3012 & 8 \\
$\mathbf{3}$ & 100 & 60 & 2710 & 17 \\
$\mathbf{4}$ & 140 & 60 & 2455 & 25 \\
$\mathbf{5}$ & 180 & 60 & 2175 & 33 \\
\hline
\end{tabular}

Table 2. Comparative metallic spring compression test at various temperature

\begin{tabular}{ccccc}
\hline $\begin{array}{c}\text { Sample } \\
\text { No }\end{array}$ & $\begin{array}{c}\text { Temperature } \\
\left({ }^{\circ} \mathbf{C}\right)\end{array}$ & Duration & Max force $(\mathbf{N})$ & $\begin{array}{c}\text { Loss of force at } 7 \mathbf{~ m m} \\
\text { compression compare to room } \\
\text { temperature (\%) }\end{array}$ \\
\hline $\mathbf{1}$ & 24 & - & 735 & - \\
$\mathbf{2}$ & 150 & 24 hours & 714 & 2.8 \\
\hline
\end{tabular}

measured during the compression test at various temperatures.

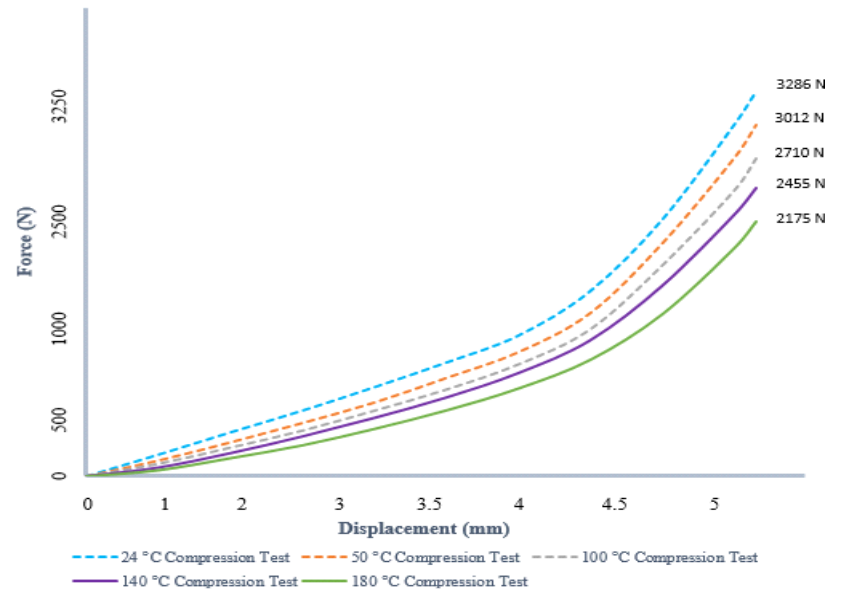

Figure 4. Compression test comparison for rubber test specimens

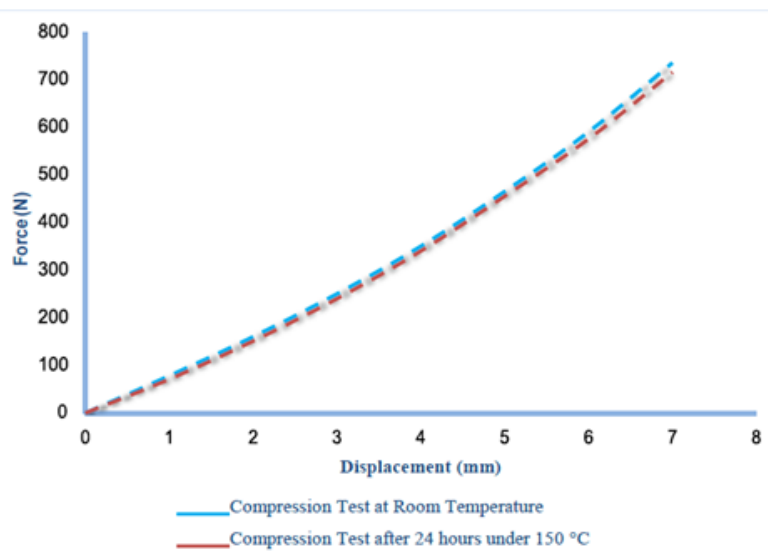

Figure 5. Compression test for metallic springs at various conditions

Figure 5 shows the compression test of metallic spring under $150{ }^{\circ} \mathrm{C}$ for 24 hours. When the measured forces are compared, it can be seen that less stiffness loss is observed compared to rubber-based test samples. The geometry of the Metallic spring itself was designed with 18.8 $\mathrm{mm}$ in length and $17 \mathrm{~mm}$ in diameter due to envelope of clutch disc design. This test was performed at more severe conditions because of the longer duration of heating compared to Figure 4. However, it can be seen that force loss occurs less than rubber test samples. Table 2 also shows a brief comparison of max loss of force.

It seems that while the NBR test samples lost its max force about $25 \%$ at max displacement, the metallic spring lost its force at about $2.8 \%$ despite more severe test conditions.

\section{Furnace Test}

In this section, the furnace test has been applied to see the comparative behavior of rubber and metallic damper under temperature. Used damper design for Metallic and rubber springs have same geometrical design, because both dampers are in design for same clutch assembly. The other consideration is to test same geometries well in terms of thermal comparison. Rubber and Metallic springs have $18.8 \mathrm{~mm}$ in length, and $17.0 \mathrm{~mm}$ in diameter.

The first target is to compare two kinds of damper and then measure to get 'Damper torque curve under cooling phase'. Figure 6 indicates the temperature measurement method. The temperature on springs measured by laser thermometer just after the test and recorded at specific intervals within time. In this test, the clutch disc assemblies using rubber and metal springs were subjected to furnace test for 60 minutes under various temperatures.

\subsection{Comparison of cooling phase after furnace test}

In this section performed comparisons of 
cooling behaviors of both springs are explained. Steel based materials have low specific heat (c) compared to rubber-based materials. It leads faster increase and decreases in temperature compared to rubber-based materials. In opposite, measured temperatures on rubber springs are observed more slowly. On average, the specific heat is accepted as $0.5 \mathrm{Kj} / \mathrm{Kg}{ }^{\circ} \mathrm{C}$ for steel-based materials, when $1.25 \mathrm{Kj} / \mathrm{Kg}{ }^{\circ} \mathrm{C}$ is accepted for rubbers.

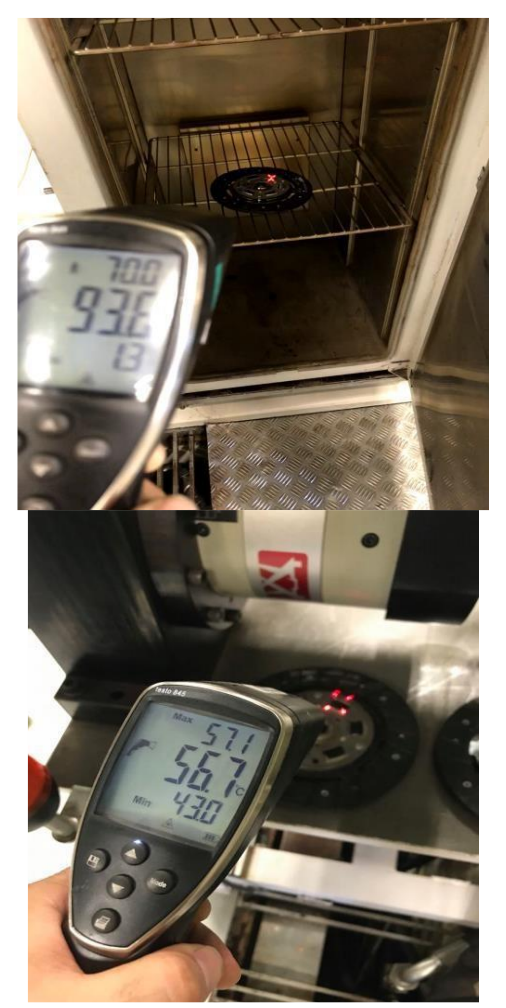

Figure 6. Furnace test and temperature measurement on metallic and rubber springs by laser thermometer

Comparative cooling phases of rubber and metallic springs after the furnace tests are indicated in Figures 7, 8 and 9. The clutches having rubber and metallic dampers were subjected to same thermal load during 60 minutes (one hour) in Furnace. Although the both damper starts the heating process with same room temperature, the materials reach the final temperatures with in difference due to material specific heat.

After the clutch discs having metallic and rubber dampers are taken out from the furnace, the laser thermometer machine reads different temperatures on the screen. Afterwards, the observing process is started to investigate the cooling behaviors of the both dampers. The metals have a rapidly cooling phase due to low specific heat capacity; conversely, the rubber cooling behaviors are too slow compared to metallic springs. These results, showed in Figures 7, 8 and 9, support the cooling behavior of the rubber spring. This case also proves that metallic springs can cool itself during driving conditions. However, rubber springs have slow cool-down comparatively. So, this case explains that rubber springs are subjected to more heat that may cause deterioration for stiffness level.

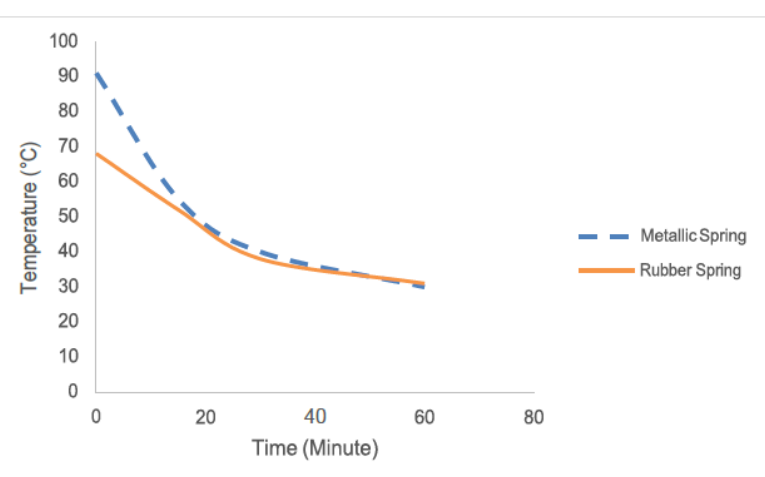

Figure 7. Comparative cooling phase after 'Furnace test under $100{ }^{\circ} \mathrm{C} 60$ minutes

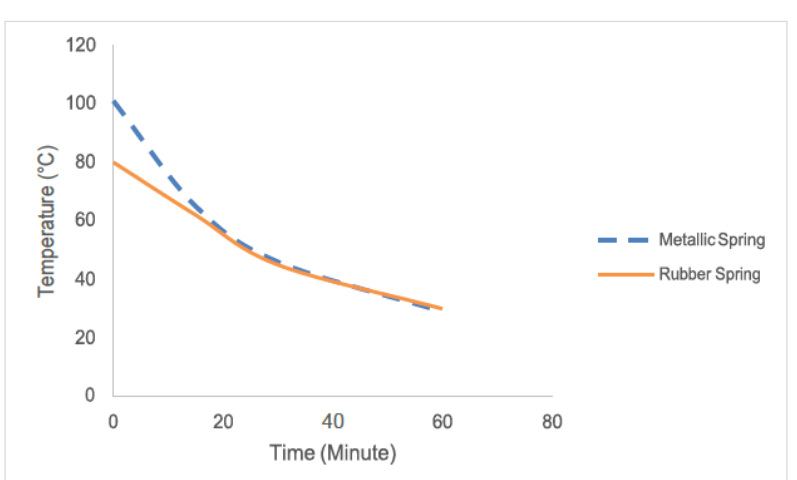

Figure 8. Comparative cooling phase after 'Furnace test under $140{ }^{\circ} \mathrm{C} 60$ minutes

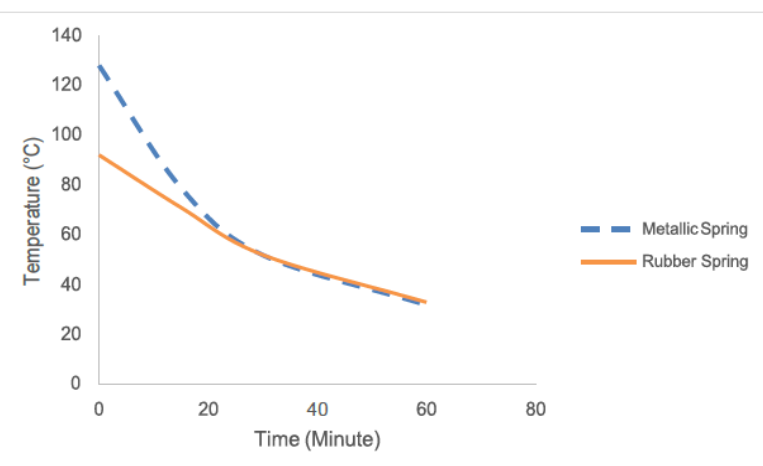

Figure 9. Comparative cooling phase after 'Furnace test under $180^{\circ} \mathrm{C} 60$ minutes

\subsection{Damper Torque Measurement after Furnace Test Comparatively with Cooling Phase}

The analysis in this section shows the damper torque characteristics of the tested parts just after the test with certain intervals. As shown in 
the previous sections, temperature increase creates the loss of stiffness due to the deterioration of polymer chains. Damper torque measurement at the various temperatures proves the stiffness behavior of the rubber spring during different operational conditions which can cause uncertain temperature levels on the clutch house.

Figure 10 shows the example damper torque curve prepared in this study, and functional measurement machine for clutch damper torque characteristics. In the compression phase, the machine compresses the disc assembly withstand the opposite force. Through this phase, the withstand torque can be calculated and the nonlinear curve is obtained. At the release phase, the opposite torque is released at the specified speed, and the force on the rubber dampers is decreasing gradually. Hysteresis is the torque loss between compression and release loads. Hysteresis occurs due to the internal energy loss of the damper springs, and the frictional loss inside the disc components. Hysteresis is required at the target specification since the generated damper torque in the engine should be filtered to increase driving comfort and components durability on the automobile.

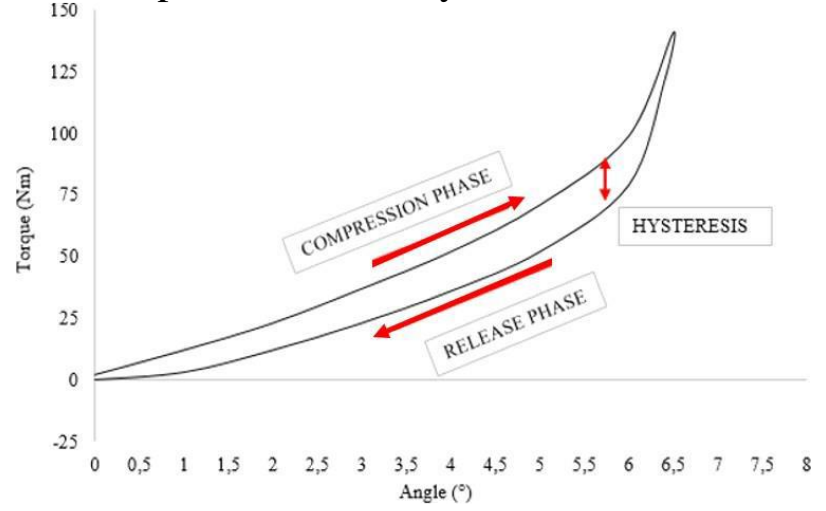

a) Clutch disc damper torque graph during measurement on function machine

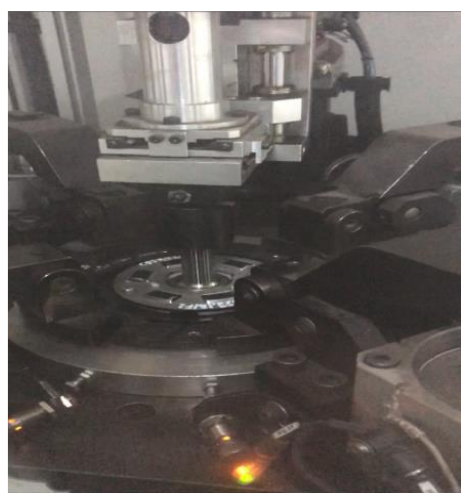

b) Damper torque measurement function machine

Figure 10. Clutch disc damper torque chart \& Damper torque measurement machine
Figures 11, 12 and 13 show the measured damper torque characteristics after furnace tests. It can be seen that just after the test the damper torque loss reaches to a meaningful level, then the damper torque levels are increased in parallel to material characterization tests showed at Section 2. The clutch disc dampers rotate up to $6.5^{\circ}$ radial angle. This value, defined via Travel $\left({ }^{\circ}\right)$ in horizontal on figures, states the torque withstand values of the rubber and metallic dampers. In conclusion, the dampers can not be compressed over than $6.5^{\circ}$ radial angle in operational condition. Also, the damper torque characteristic can be seen clearly in terms of rubber material's non-linear behavior in these damper torque graphics (Fig. 11, 12 and 13). Due to non-linear force reaction behavior in rubber springs, rubber stiffness increases in parallel to compression in nonlinear manner which leads to non-linear withstand torque value metallic dampers. Sudden increase after $6.5^{\circ}$ radial angle explains the rotational limits of clutch design. This case means that up to $6.5^{\circ}$ radial angle the clutch dampers damp the vibration, after this value, the damper design showes rigid characteristics. This case also means that this clutch design suitable for around the engine producing $100 \mathrm{Nm}$ torque, after this value $(100 \mathrm{Nm})$ clutch damper design does not meet the vehicle comfort requirements.

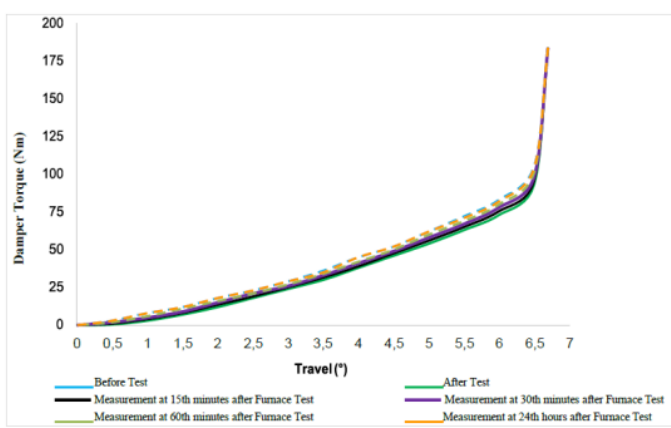

Figure 11. Damper torque curve for clutch damper disc with rubber springs - ' 60 minutes under $100{ }^{\circ} \mathrm{C}$ furnace test

In case the general overview is done between the Figure 11, 12 and 13, the maximum damper torque loss can be seen on Figure 13 which subjected to $180{ }^{\circ} \mathrm{C}$ during 60 minutes in Furnace. Conversely, Figure 11, subjected to minimum temperature comparatively, shows the least torque losing. Table 3 is the brief information of Figures 11, 12 and 13. The maximum damper torque loss is observed to increase with environmental temperature. 
Table 3. Comparison of max damper torque after several temperatures

\begin{tabular}{cccccc}
\hline Sample No & $\begin{array}{c}\text { Temperature } \\
\left({ }^{\circ} \mathbf{C}\right)\end{array}$ & $\begin{array}{c}\text { Duration } \\
\text { (Minutes) }\end{array}$ & $\begin{array}{c}\text { Max Damper } \\
\text { Torque Before } \\
\text { Furnace Test }\end{array}$ & $\begin{array}{c}\text { Max Damper } \\
\text { Torque After } \\
\text { Furnace Test (Nm) }\end{array}$ & $\begin{array}{c}\text { Max Damper Torque } \\
\text { Loss (\%) }\end{array}$ \\
\hline 1 (Figure 11) & 100 & 60 & 105 & 93 & $11 \%$ \\
2 (Figure 12) & 140 & 60 & 106 & 92 & $13 \%$ \\
3 (Figure 13) & 180 & 60 & 108 & 91 & $16 \%$ \\
\hline
\end{tabular}

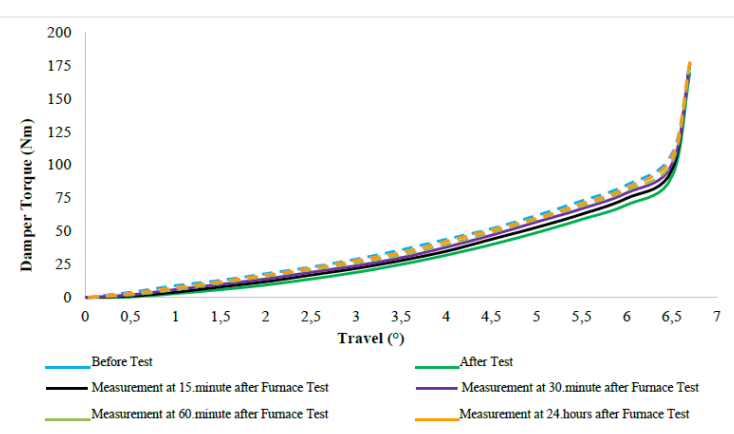

Figure 12. Damper torque curve for the clutch disc with rubber springs - ' 60 minutes under $140{ }^{\circ} \mathrm{C}$ furnace test

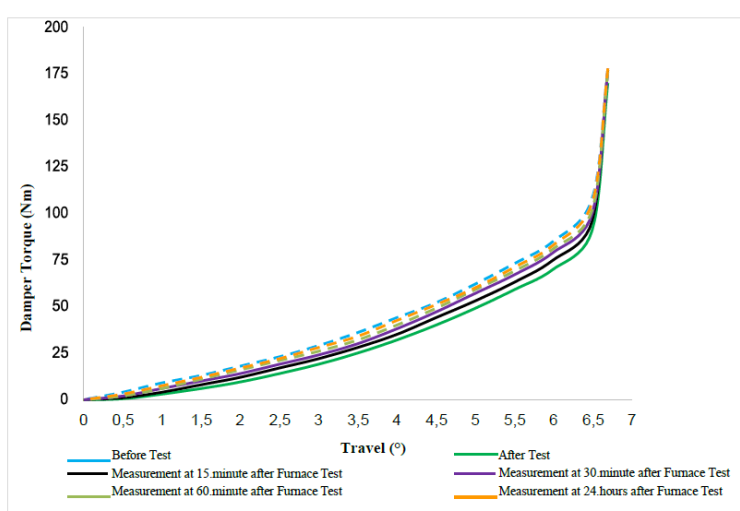

Figure 13. Damper torque curve for the clutch disc with rubber springs - ' 60 minutes under $180^{\circ} \mathrm{C}$ furnace test

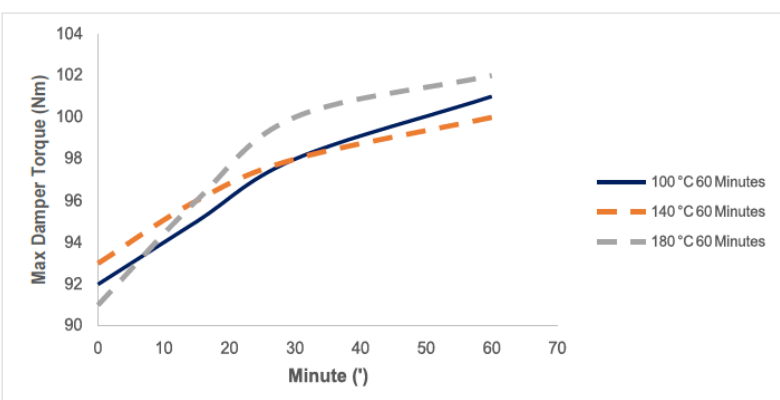

Figure 14. Comparisons of damper torque behavior after test-Max damper torque (Nm) vs. Time (Minute)

Figure 14 explains and summarizes the Figure 11,12 and 13 with different aspect. This figure shows the maximum damper torque increase at the cooling phase within the time. At first minutes just after the test, the rapid stiffness increase can be obtained from the graphics. As time progresses, increase in damper torque levels slows down. Figure 14 also explains the importance of clutch house environmental condition during driving condition with low, intensity and medium traffic cases, therefore during intensiv traffic condition, rubber springs are supposed to have more stiffness loss because of the instense slippage in clutch faces. In same behavior, rubber dampers need significant time to repair its broken polymer chains due to thermal loads, and turn back to the close beginning damper torque condition.

\section{Conclusion}

This study includes novel experimental approaches to the mechanical behaviors of rubber and metallic springs under thermal and dynamic conditions. Metal-based materials have low specific heat compared to rubber materials. This case provides more heat distribution and more stable material properties for steel. In comparison, rubber-based materials tend to lose their material stability under incremental thermal load. Besides, high specific heat prevents the heat distribution in rubber materials and causes additional stiffness loss in parallel to polymer chain deterioration. In order to reveal the damper torque behavior of rubber springs in driving condition, material test, and final product bench tests were performed to (NBR) rubber material test samples and clutch disc, and then the obtained results were analyzed comparatively with clutch disc using metallic springs. Results show that the rubber-based materials should be reinforced with the required material content due to high thermal loads in case they have used on automobiles as clutch discs. Furthermore, the study revealed that the rubber dampers have to be designed with more safety factor ratios in terms of stiffness level compared to metallic springs to keep enough damping during product life.

\section{Acknowledgments}

This study has been performed with the collaboration of Valeo Automotive Systems and Bursa Uludag University.

\section{References}

1. Adamowicz, A., "Effect of Convective Cooling on Temperature and Thermal Stresses 
in Disk during Repeated Intermittent Braking", Journal of Friction and Wear, Vol.37, Issue.2, pp.107-112, 2016.

2. Gkinis, T., Rahmani, R., Rahnejat, H., Mahony, M., "Heat generation and transfer in automotive dry clutch engagement", Applied Physics \& Engineering, Vol. 19, Issue.3, pp. 175-188, March 2018.

3. Zhang, Z., Zhang, H., "Viscoelastic Parameter Identification based StructureThermal Analysis of Rubber Bushing", Global Journals of Research in Engineering, Vol.14, Issue.3 Version 1.0, 2014.

4. Melnik, R.V.N, Strunin, D.V., Roberts, A.J., "Nonlinear Analysis of Rubber-Based Polymeric Materials with Thermal Relaxation Models", Numerical Heat Transfer, Part A, 47: 549-569, 2005.

5. Zhang, Z., Zhang, H., "FEA based Dissipation Energy and Temperature Distribution of Rubber Bushing", International Journal of Engineering Research and Applications, ISSN: 2248-9622, Vol.6, Issue.1, (Part - 2), pp.48-56, 2016.

6. Bani, M. S. , Stamenkovi, D.S. , Miltenovi, V.D., Milosevic, M.S., Miltenovi, A.V., Djeki, P.S., Rackov, M.J., "Prediction Of Heat Generation In Rubber Or Rubber-Metal Springs", Thermal Science, Vol. 16, Issue. 2, pp. 527-539, 2012.

7. Genc, M. O., Kaya, N., "Design and verification of elastomer spring damping system for automobile powertrain systems", Journal of the Faculty of Engineering and Architecture of Gazi University 35:4, 1957-1971, 2020.

8. Monsia, M. D., "A Simplified Nonlinear Generalized Maxwell Model for Predicting the Time-Dependent Behavior of Viscoelastic Materials", World Journal of Mechanics, Vol. 1, Issue.3, pp. 158-167, 2011.

9. Mohammed, M.A., "Visco-Hyperelastic Model for Soft Rubber-like Materials", Sains Malaysiana, Vol: 43(3), pp. 451-457, 2014.

10. Pacheco, J. L., Bavastri, C.A., Pereira, J.T., "Viscoelastic Relaxation Modulus Characterization Using Prony Series", Latin American Journal of Solids and Structures, Vol:12, pp. 420-445, 2015.

11. Wu, Y., Wang, H., Li, A., "Parameter Identification Methods for Hyperelastic and Hyper- Viscoelastic Models", Applied Sciences, Vol.6, Issue.386, 2016.
12. Ali, A., Hosseini, M., Sahari, B., "A Review of Constitutive Models for Rubber-Like Materials", American J. of Engineering and Applied Sciences, 3 (1): 232-239, 2010.

13. Abubakar, I. J., Myler, P., Zhou, E., "Constitutive Modelling of Rubber Seal Material under Compressive Loading", Modeling and Numerical Simulation of Material Science, Vol.6, pp. 28-40, 2016.

14. Jadhav, N., Bahulikar, S.R., Sapate, N.H., "Comparative Study of Variation of Mooney-Rivlin Hyperelastic Material Models under Uniaxial Tensile Loading", Vol.2, Issue.4, IJARIIE-ISSN(O)-2395-4396, 2016.

15. Kaya, N., "Shape Optimization of Rubber Bushing Using Differential Evolution Algorithm", Hindawi Publishing Corporation Scientific World Journal Volume, Article ID 379196, 2014.

16. Marvalova, B., "Viscoelastic Properties of Filled Rubber. Experimental Observation and Material Modelling ", Engineering Mechanics, Vol.14, Issue.1/2, pp.81-89, 2007.

17. Sun, W., Li, Y., Huang, J., "Nonlinear Characteristics Study and Parameter Optimization of DMFRS", SAE International Journal of Passenger Cars-Mechanical Systems, Vol.4, Issue.2, pp.1050-1057, 2011.

18. Genc, M. O., Kaya, N., Konakci, S., "Experimental Verification of Rubber Clutch Spring Damper Torque Behavior in TimeDependent Manner and System Optimization using Simulated Annealing Algorithm Integrated with 1-D Modeling", https://doi.org/10.1115/IMECE2019-10965, Proceedings of ASME, Utah, USA, 2019. 